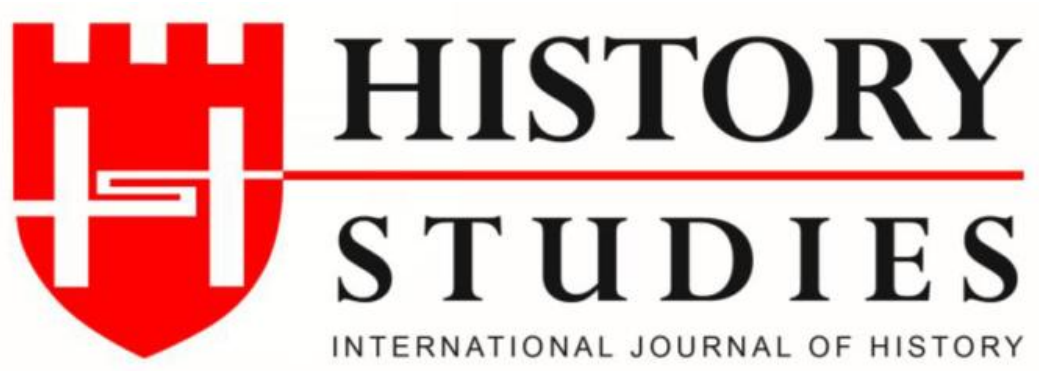

ISSN: 13094173 (Online) 1309 - 4688 (Print)

Volume 12 Issue 3, June 2020

DOI Number: 10.9737/hist.2020.871

Araştırma Makalesi

Makalenin Geliş Tarihi: 26.04.2020 Kabul Tarihi: 25.05.2020

Atıf Künyesi: Muhammed Fazıl Himmetoğlu, “Eski Çağda Kenevir Bitkisinin Kullanım ve Yayılımı Hakkında Yeni Bir Değerlendirme", History Studies, 12/3, Haziran 2020, s. 1129-1142.

\title{
Eski Çağda Kenevir Bitkisinin Kullanım ve Yayılımı Hakkında Yeni Bir Değerlendirme
}

\author{
A New Evaluation on The Use And Distribution of Hemp Plant in Ancient Age
}

\author{
Dr. Muhammed Fazll Himmetoğlu \\ ORCID No: 0000-0002-1315-5736 \\ Osmaniye Korkut Ata Üniversitesi
}

Öz: Eski çağ insanları çevreleriyle uyumlu bir şekilde yaşamışlarıdır. Yaşadıkları coğrafyanın şartlarına ayak uydurdukları gibi diğer coğrafyalarda yaşayan toplumlarla da kültür alış verişi içerisinde olmuşlardır. Kenevir de işte bu kültür alış verişi sayesinde dünyaya yayılmış endüstriyel bir bitki olarak görülmektedir. Neolitik dönemde Orta Asya'da ortaya çıkan bu bitki eski çağda uzak doğuda birçok alanda kullanılmıştır. Kenevir Hint dünyasına da kültür alış verişi sayesinde taşınmış ve Hint coğrafyasında da kullanılmıştır. Fakat kenevirin Ortadoğu, Anadolu ve Avrupa'ya ulaşması konusunda bazı görüş ayrılıkları vardır. Kimi araştırmacılara göre kenevir eski çağda Mezopotamya, Anadolu ve Avrupa'ya erken tarihlerde gelmiştir. Bunun karşısındaki fikre göre de kenevir eskiçağın son döneminde bu coğrafyalara girmiştir. Bu çalışmada bu fikir ayrılıklarına yeni bir yorum getirilecektir. Diğer taraftan kenevirin kültür aktarımı ile eski çağda Avrasya'nın batı parçasına er veya geç ulaşmasına karşın doğu ile aynı seviyeyi geç yakalamasının nedenleri sonuç kısmında tartışılacaktır.

Anahtar Kelimeler: Kenevir, Eski Çağ, Asya, Avrupa, Akdeniz

Abstract: Ancient age people lived in harmony with their environment. In addition to keeping up with the conditions of the geography they live in, they have also been in cultural exchange with the communities living in other geographies. Hemp is seen as an industrial plant spread around the world thanks to this cultural exchange. This plant, which emerged in Central Asia during the Neolithic period, was used for many areas in the Far East during ancient times. Hemp was also transported to the Indian world through cultural exchange and was also used in the Indian geography. However, there are some differences of opinion regarding the transportation of hemp to the Middle East, Anatolia, and Europe. According to some researchers, the hemp arrived at Mesopotamia, Anatolia, and Europe in the early dates during ancient times. According to the opposite idea, the hemp entered these geographies in the last period of ancient times. In this study, a new interpretation will be brought to these differences of opinion. On the other hand, although the hemp reached the western part of Eurasia sooner or later in ancient times with cultural transfer, the reasons why the hemp catches the same level as the east later will be discussed in the conclusion section.

Keywords: Hemp, Ancient Age, Asia, Europe, Mediterranean 


\section{Giriş}

Çalışmanın konusu olan kenevirin bir bitki olması ve tıp, dokuma gibi faklı alanlarda kullanılmış olması nedeniyle botanik, tekstil tarihi ve tıp tarihi gibi farklı alanlarla ilgili literatür taramasına gidilmiștir. Bu nedenle eski çağ için oldukça önemli bir hammadde olan Cannabis Sativa bitkisi üzerine yapılan bu çalışma disiplinler arası bir kimliğe sahip olacaktır.

Kenevir bitkisinin tarihi seyirdeki yerinin ele alındığı önemli kaynaklardan biri Kaliforniya Üniversitesinde basılmış ve tam künyesi Clarke, C. M., Merlin, M. D., (2013) Cannabis Evolition And Ethnobotany, University Of California Press, Los Angales olan eserdir. Bu kitap çalışmasında en eski devirlerden günümüze kadar kenevir bitkisinin kullanıldığı yerler ve şartlar ortaya konulmuştur. Modern kaynaklar arasında yer alan bu çalışmanın yanında Duwall, C., (2014), Cannabis, Reaktion Books, London, künyeli eser bu çalışmaya yön veren metinler arasında olup botanik bilimi dairesinde keneviri değerlendirmekle beraber yine tarihi seyir içindeki kenevirin yeri hakkında bilgiler sunmaktadır. Modern arkeolojinin doğduğu dönemde Mezopotamya bitkileri üzerine çalışmaları olan R. C. Thompson'ın Mezopotamya tabletlerini okuyup kenevir üzerine yaptığ değerlendirmelerden de bu çalışmada faydalanılmıştır. Thompson'un değerlendirmesi bir makale olup makale künyesi Thompson, R. C.,"Assyrian Prescriptions For Treating Bruises Or Swellings", The American Journal Of Semitic Languages And Literatures, Vol. 47, No. 1, 1930, s. 1-25 şeklindedir. Kenevirin tıp tarihi içindeki yeri için Bayat, A. H., (2016), Tup Tarihi, Zeytin Burnu Belediyesi Merkez Efendi Geleneksel Tip Derneği, İstanbul künyeli eseri ve Carod, F.J.-Artal, (2013), "Psychoactive Plants In Ancient Greece", Neurosciences and History 2013; 1 (1): 28-38 künyeli makale istifade edilen çalışmalar arasındadır. Hindistan coğrafyası için Zuardi, A. W., "History Of Cannabis As A Medicine: A Review", Rev Bras Psiquiatr. 2006; 28(2), s.153-157 künyeli makale kenevirin meditasyon amaçlı kullanımı hakkında bilgiler vermektedir. Diğer taraftan dil bilimsel kaynak olarak kenevir bitkisinin Asur ve Akkadca'daki dillerindeki yeri için The Assyrian Dictionary Of The Oriental Institute Of The University Of Chicago adl 1 sözlük eserden istifade edilmiştir.

Kenevirin eski çağ dokuma tarihindeki yeri için Dölen, E., (1992), Tekstil Tarihi, Marmara Üniversitesi, İstanbul, künyeli eser, Anadolu'daki kenevir varllğı hakkında ip uçları veren bir eserdir. Bunun yanında 2013 Çatalhöyük kazı raporu kenevirin Anadolu'da görüldüğü en eski zamanı araştırmacılara sunmaktadır. Hodder, Ian. "Çatalhöyük 2013 Kazı Raporu”, Dünya Kültür Miras Listesi'ne Alınan Bir Kazıda Çalışmak, catalhoyuk.com, 23. 04. 2020 künyeli rapor dijital ortamda faydalanmaya müsait bir haldedir. Eski çağda Mezopotamya ve Anadolu arasındaki tekstil ticaretinin birinci elden kaynağı olan Kültepe Tabletleri’ni inceleyen Cahit Günbattı'nın çalışmaları da çalışmadan yararlanılan eserler arasındadır. Eserin tam künyesi Günbatt1, Cahit, Kültepe-Kaniş Anadolu'da İlk Yazı İlk Belgeler, Kayseri Büyükşehir Belediyesi Kültür Yayınları, Kayseri 2017 şeklindedir. Yine bu bağlamda faydalanılan bir diğer çalışma makale şeklinde olup künyesi, Cebesoy S. Saba, "Kapadokya Tabletlerinde Geçen Dokuma Ürünleri”, Anadolu Medeniyetler Müzesi 1994 Yıllı̆̆g, Ankara 1995, s. 164188. Çalışma da daha birçok yerli ve yabancı kaynak kullanılmış olup bunlar kaynakça bölümünde yer almaktadır.

Eski çağ toplum ve medeniyetleri besin maddesi olarak kullanmak, ilaç elde etmek, örtünmek, ticaretini yapmak vs. birçok sebepten dolayı bitkilerden istifade etmişlerdir. $\mathrm{Bu}$ bağlamda çalışmanın amaçlarından biri günümüzde narkotik unsur olarak görülen fakat birçok sektörde hammadde olarak kullanılan kenevir bitkisinin eskiçağ halkları tarafindan da kullanıldığını, ekilip tüketildiğini ortaya koymaktır. Keneviri kullanan eski çağ toplumlarının hangi amaçla bu bitkiden faydalandıklarını, hangi özelliklerini ne şekilde değerlendirdiklerini 
izah etmek çalışmanın ikincil amacı olmuştur. Literatür taraması ve okuması yapıldığında eski çağda kenevirin varlığı ve kullanımı Çin, Japonya, Kore ve Hindistan için reddedilemezken, Mezopotamya ve Anadolu'daki varlıkları konusunda tartışmalar olduğu görülmüştür. $\mathrm{Bu}$ tartışmaya yeni bir bakış açısı getirmek çalışmanın bir diğer amacını doğurmuştur. Son olarak ise keneviri kullanan eski çağ halklarının nasıl bir avantaja sahip olduklarını tespit etmek çalışmanın nihai hedefi olmuştur.

Çalışma yöntemi olarak önce literatür taraması yapılmıştır. Daha sonra ulaşılan birincil kaynaklar, yerli ve yabancı derleme ve araştırma eserleri mukayeseli bir şekilde okunmuştur. Elde edilen veriler değerlendirilmiştir. Bu değerlendirme doğrultusunda çalışmanın bölümleri oluşturulmuştur. Bu bölümler bitkinin kullanıldığı coğrafyaların isimleri ile şekillendirilmiştir. $\mathrm{Bu}$ coğrafyalarda yapılan arkeolojik verilere başvurulmuştur. Ulaşılan arkeolojik verilerle yazılı kaynaklar mukayese edilip sonuca ulaşılmıştır.

\section{1-Doğu Asya:}

Günümüzden 12 bin yıl önce holosen çağının başlamasıyla ortaya çıtığı düşünülen kenevirin ana vatanının merkezi Asya olduğu düşünülmektedir ${ }^{1}$. Bu dönemde avcı toplayıcılar bu bitkinin tohumlarını besin maddesi olarak toplayıp kullanmışlardır ${ }^{2}$. Yaklaşık 1000 yıl sonra MÖ 9 binlerde kenevir tohumlarının Çin'e kadar ulaştığı anlaşılmaktadır ${ }^{3}$. MÖ 8 binlerde Taywan'da da lif izleri bulunan bu bitkinin yabani olarak doğada var olup zamanla insan eliyle yayılıp ehlileştirildiği anlaşılmaktadır. Çin'de erken devirlerde kenevir insanlar tarafından tarımsal bir değer haline getirilip yağından faydalanılmıştır ${ }^{4}$. Bu yağ kenevir tohumlarının ezilmesiyle elde edilmiştir. Yeşilimsi ve lezzetli olan kenevir yağı insanlar tarafından uzun bir süre tüketilmiştir ${ }^{5}$.

MÖ 4. binde Çin'de besin olarak tüketilen kenevir ve kenevir tohumu, sonraki zamanlarda aynı coğrafyada tıbbi bir malzeme olarak karşımıza çıkmaktadır. Bu dönemde Çin'de İmparator Shen-Nung (MÖ 2700'lü yıllar) iktidardadır. Onun döneminde kenevir sitma, kısırlık, romatizma, bağırsak bozuklukları gibi hastalıklara karşı ilaç olarak kullanıldığı görülmektedir ${ }^{6}$. MÖ 3 binlerde kültürel ekolojinin yayılması sayesinde Kore Yarımadasına ulaşan kenevir yarımadanın güneyinde tekstil ürünler için hammadde olarak kullanılmaya başlamıştır ${ }^{7}$. Daha sonraki asırlarda Kore ve Japonya'da tekstille beraber halat yapımında da kullanılan kenevir MÖ 16. asırda Çin'de psikoaktivite aracı olarak kullanıldığına dair yazılı kanıtlar mevcuttur ${ }^{8}$. Bu asırdan itibaren Çin topraklarında kenevir çok önemli bir üretim malzemesi haline gelmiştir. Onun ekiminde Çinli üreticiler giderek ustalaşmışlardır. $\mathrm{Bu}$ ustalıklarını da yazıya döküp üretim geleneğinin kaliteli bir şekilde ilerlemesini sağlamışlardır. Yazıya dökülen tekniklerden biri kayıtlara şu şekilde geçmiştir:

"Eğer erkek keneviri polenlerini saçmadan çıkarırsak gerekli tozlaşma yapılamaz. Ama zamanında çıkarırsak dişi kenevir iyi bir şekilde tozlaşır ve en iyi ürünü verecektir"’’.

\footnotetext{
${ }^{1}$ Robert, C. Clarke-Mark D. Merlin, Cannabis Evolition And Ethnobotany, University Of California Press, Berkeley, Los Angeles, London, 2013, s. 52

${ }^{2}$ Age, s. 17

${ }^{3}$ C. Duwall, Cannabis, Reaktion Books, London, 2014, s. 30

${ }^{4}$ T. Karche-M. R. Singh, "The Application Of Hemp (Cannabis Sativa L.) For A Green Economy: A Review", Turkish Journal of Botany, 43, 2019, s. 710 
$\mathrm{Bu}$ cümleden anlaşıldığına göre kenevirin eril ve dişil iki cinsinin olduğu çoktan Çinli uzmanlarca keşfedilmiştir.

1972'de önemli bir arkeolojik kazı yapılmıştır. Bu kazı sayesinde MÖ 13. asırdan 3. asra kadar iktidarda kalmış olan Chou hanedanına ait bir mezar alanı keşfedilmiştir. Arkeologlar bu alanda bazı silah ve metal parçalarının yanında kumaş parçalarına da ulaşmışlardır. Daha sonra araştırmacılar kumaşlarda yapılan incelemelerde bu parçaların kenevirden elde edildiğini saptamışlardır ${ }^{10}$. Anlaşıldığı kadarıyla kenevir bu dönemde uzak doğunun giyim endüstrisinin hammaddesi haline gelmiş̧ir.

Eski çağda uzak Asya'da tıp, tekstil ve mükeyyifat aracı olarak kullanılan kenevirin bir başka kullanıldığı alan ise kâğıt üretimi olmuştur. Kâğıt çok eski zamanlarda Çin'de bitkilerle üretilen bir üründür. Kâğıt üretiminde kullanılacak bitkilerin bazı özelliklere sahip olması gerekmektedir. Yoğun lifli ve selüloz oranı yüksek bitkiler bunun için uygundur. Eski çağda Çin'de kâğıt üretimi için en geçerli bitki bambu ağacıdır. Fakat ağaç kabuğu, dut, keten, pamuk ve kenevir de kâğıt üretimi için kullanılmıştır. Kenevirin Çin'de kâğıt yapımında kullanılması diğer sektörlerde kullanılmasından daha geç bir tarihe denk gelmektedir. Çin kaynakları üzerine çalışan araştırmacıların ortaya koyduğu bilgiye göre kenevirin kâğıt üretiminde kullanılması Batı Han Hanedanı zamanında (MÖ 206- MS 8) gerçekleşmiştir ${ }^{11}$. Arkeologlar İmparator Wu'nun mezarında kenevirden yapılmış el yapımı kâğıt bulmuşlardır ${ }^{12}$. Kenevir kâğıdı kenevirin kendisi gibi sağlam ve dayanıklıdır. Sert olsa da bükülebilir ve su geçirmez bir yapıya sahiptir. Bu nedenle Çin'de bu kenevir kâğıdının hat kâğıdı ve kitap kâğ $d_{1}$ olarak kullanıldı ğı araştırmacılar tarafından ortaya konulmuştur ${ }^{13}$.

Eski çağda Çin'de gida, tekstil, ilaç, kâğıt gibi endüstriyel ürünlerin hammaddesi haline gelen kenevir halat, bez ve yelken bezi üretiminde de kullanıldığ 1 anlaşılmaktadır. Han hanedanlığı zamanında (MÖ 206- MS 8) kenevirden yapılma yelkenler sayesinde Çin önemli bir deniz gücü haline geldiği bilinmektedir. Yelken bezi için kullanılan kanvas kelimesi köken olarak Latincede cannabis Grekçe de kannabis olarak karşımıza çıkar ki bu kelimeler kenevir anlamına gelmektedir ${ }^{14}$. Eski çağda Çin denizciliğinin ilerlemesinin arkasında kenevirden elde edilen halat ve yelken teknolojisinin yer aldığı açıktır. Lynda Shaffer'a göre Çinli denizciler Baharat Adalarına ve Java Adasına kadar deniz ticaret ağı geliştirmişlerdir ${ }^{15}$.

\section{2-Hindistan:}

Kenevir Sanskrit dilinde Vijaya şeklinde telaffuz edilmektedir. Hint dilinde ise bhang şeklinde yazılmaktadır ${ }^{16}$. MÖ 15. asırda Hindistan'da kenevirin kullanıldığına dair verilere ulaşılabilmektedir. Tek istisna olarak Sri Lanka'da esrar veya kenevir izlerine İngilizler gelene kadar rastlanmamıştır ${ }^{17}$. Hindistan'da kenevirin psikoaktivite (esrar) aracı olarak kullanıldığ 1 araştırmacılar tarafından ileri sürülmektedir. Bazı araştırmacılar ise bunu soma bitkisi ile

\footnotetext{
${ }^{10}$ Ernest L. Abel ., Marihuana The First Twelve Thousand Yeras, Springer Science Business Media, New York 1980 , s. 4-5

11 Tsuen-Hsuin Tsien, "Raw Materials for Old Papermaking in China", Journal of the American Oriental Society, Vol. 93, No. 4, 1973, s. 510

12 Mia Touw, “The Religious And Medicinal Uses Of Cannabis In China, India and Tibet”, Journal of Psychoactive Drugs, Vol. 13(1), 1981, s. 1, 2

${ }^{13}$ Tsuen-Hsuin Tsien, agm. s. 512

${ }^{14}$ David E. Newton, Age, s.324

15 Lynda Shaffer, "Southernization", Teaching World History: A Resource Book, Editor: Heidi Roupp, M. E. Sharpe, London 1997, s. 113

${ }^{16}$ M. Kuddus- I. A. Ginavani-A. El-Hazimi, "Cannabis sativa: An ancient wild edible plant of India”, Emir. J. Food Agric. Vol. 25 No: 10,2013 s. 736

17 Robert, C. Clarke-Mark D. Merlin, Age, s. 89
} 
karıştırsa da kenevirin başlı başına bir bitki olarak Hindistan'da bilinip ondan istifade edildiği açıktır. Hindistan'da MÖ 15. asırda üretimine başlanan kenevir yüksek bir ihtimalle Çin'den ithal olarak getirilip ekimi yapılmıştır. Hint kültürünün en eski belgelerinden Vedalar'da kenevirin psikoaktif etkisinden bahsedildiği araştırmacılar tarafından saptanmıştır. Vedalar'a göre kenevir dünyaya cennetten düşen bir bitkidir. Artharvaveda'nın bir bölümünde kenevirin yani esrarın insanı endişe ve korkulardan kurtardığı söylenmektedir ${ }^{18}$. Ayrıca Hindistan kültüründe 5000 yıllık bir geçmişe sahip olan Ayurveda tıp kitabında kenevirin önemli bir ilaç olarak tanıtıldığ 1 araştırmacılar tarafindan ileri sürülmektedir. Buradaki bilgiye göre kenevir ishal, epilepsi, romatizma, gastrit, iştahsızlık, bulantı, kabızlık, ateş, sarılık, bronşit, cüzzam, diyabet, soğuk algınlığı, adet sancısı, verem, astım, gut ve sıtma gibi birçok hastalığa iyi gelen bir bitkidir ${ }^{19}$.

Eski çağda Hindistan, kenevirin Çin'den Ortadoğu'ya, Anadolu'ya ve batı dünyasına ulaşmasında önemli bir dağılım noktası olduğu iddia edilmektedir ${ }^{20}$. Daha yakın tarihlere gelinecek olursa MÖ 5. asırdan MS 1. asra kadar ki dönemde de Tibet'ten Hindistan ovalarına kadar kenevirin kullanıldığı bilinmektedir. Kenevirin burada tıp ve mükeyyifat maddesi olarak kullanıldığ 1 gibi bir takım dini ritüellerde de kullanıldı̆̆ 1 açıktır. İnsanda ruhsal haller yaşatması, zihinsel değişimlere yol açması, kullanan kişinin boyut değiştirdiğine inanmasına yol açmışıır ${ }^{21}$. Başka bir bilimsel çalışmaya göre kenevirin dini bir psikoaktivite aracı olarak kullanılmaya çok daha önceler de MÖ 2500'lü yıllarda başlanmıştır. Onu kullanan rahipler Şamanizm de olduğu gibi transa geçip boyut değiştirdiklerine inanmışlardır ${ }^{22}$. Hint tanrılarından Shiva ile esrar arasındaki ilişki oldukça derin bir tarihi bağa sahip gibi durmaktadır. Bunun yanında MÖ 1000'li yıllardan itibaren Tantrik Budizm'in etkisiyle meditasyon aracı olarak da kullanıldığı kaynaklarda geçmektedir ${ }^{23}$. İlaç, lif ve eğlence için kullanılan kenevirin Hindistan ve civarı için kutsal bir kimliği de sahip olduğu anlaşılmaktadır ${ }^{24}$.

\section{3-Mezopotamya}

Mezopotamya'da dünya tarihini başlatacak bir medeniyet kuran Sumerliler'in kenevir bitkisinden haberdar olduğu ileri sürülmektedir. Sumerliler keneviri bitlenme, epilepsi ve nörolojik hastalıkları gidermede kullandıkları iddia edilmektedir ${ }^{25}$. Sumerliler, hastalıkların kötü ruhların insanları etkilemesiyle ortaya çıktığına inanmışlardır. Dolayısıyla Sumerlilere göre hastaya yapılacak tıbbi müdahalenin sihirli bir ritüelle birlikte yapılması gerekmektedir. Bu ritüellerde kenevirin önemli bir rol oynadığı düşünülmektedir ${ }^{26}$. Fakat burada Hindistan'da olduğu gibi bir vecd hali olarak kullanıldığı şüphelidir. Zira bununla ilgili ciddi deliller kaynaklarda mevcut değildir.

\footnotetext{
${ }^{18}$ David E. Newton., Age, s. 17

${ }^{19}$ C. Bennet, "Cannabis in the Ancient World", https://weekendsatbellevue.com/pdfs/pot-book/bennett.pdf, 20.04. 2020

${ }^{20}$ B. Warf, "High Points: An Historical Geography Of Cannabis", Geographical Review, 104, 4, New York, s. 433

${ }^{21}$ Mark D. Merlin, "Archaeological Evidence for the Tradition of Psychoactive Plant Use in the Old World", Economic Botany, Vol. 57, No. 3, New York, 2003, s. 314

${ }^{22}$ Ümit H. Sayın, "The Consumption Of Psychoactive Plants During Religious Rituals: The Roots Of Common Symbols And Figures In Religions And Myths", NeuroQuantology, No. 2, 2014, s. 291

${ }^{23}$ A. W. Zuardi, "History Of Cannabis As A Medicine: A Review", Rev Bras Psiquiatr, 28 (2), 2006, s. 154

${ }^{24}$ T. Karche-M. R. Singh, agm, s. 712

25 E. B. Russo, "The Pharmacological History Of Cannabis", Chapter 2, Constituents, History, International Control, Cultivation, And Phenotypes Of Cannabis, Oup-First Uncorrected Proof, May 12, 2014, s. 23

${ }^{26}$ C. Rätsch, Marijuana Medicine: A World Tour Of The Healing And Visionary Powers Of Cannabis, Healing Arts Press, Rochester-Newyork Vermonts, 2001, s. 82
} 
Akadlılar'ın bu bitki için kullandığı kelimenin qunnabu veya qunnubu' olduğu ileri sürülmüştür. Yine iddialar göre Akad döneminde bu bitkinin medikal bir bitki olarak kullanıldığı gibi bu bitkinin çiçeği güzel koku ve parfüm yapımında da kullanılmıştır ${ }^{27}$. Fakat Akad döneminde de bu bitkinin bir narkotik unsur olarak kullanıldığına dair bir bilginin yazılı olmadığı gibi qunabbu olarak isimlendirilen bitkinin kenevir olduğu da şüphelidir. Nitekim önemli bir kaynak olan The Assyrian Dictionary Of The Oriental Institute Of The University Of Chicago'da bu isim için kenevir olabilir ifadesi yer almaktadır. Fakat bu ihtimali destekleyecek arkeolojik veriye rastlanmamıştır.

Bazı kaynaklara göre Mezopotamya'da kenevir için kullanılan diğer isimler azallû ve gurgurru $^{28}$ 'dur. $\mathrm{Bu}$ isimler hem Akad hem de Asur kaynaklarında karşımıza çıkmaktadır. azallû kelimesi Akadca'da medikal bir bitki olarak geçerken keneviri işaret ettiğgine dair bir veri yoktur ${ }^{29}$. Aynı şey gurgurru için de söylenebilirr ${ }^{30}$. R. C. Thompson, makalesinde Asur tabletlerinde azallûnun geçtiği iki belgeyi incelemiştir. Bu belgeler No. 236. AM, 87, 5 (K. 3201), No. 243. $A M$, 89, 1 (K6261) numaralı tabletlerdir. Bu tabletlerde Azallû adında bir bitkinin diğer bitkilerle birlikte bazı hastalıklar için ilaç olarak kullanıldığ geçmektedir $^{31}$. Fakat azallû olarak geçen bitkinin kenevir olduğu şüphelidir. Zira bu bilginin verildiği ve yorumlandığı kaynaklar bir hayli eskidir. Ayrıca yazıtlarda geçen isimler kenevire ait olsalardı arkeolojik kalıntılara ulaşılması ve belgelenmesi gerekmektedir. Bu noktada kimi araştırmacılar (Prof. Dr. H. Helbaek) bu kenevir bitkisinin eski çağda Mezopotamya'ya ve Anadolu'ya hiç uğramadığını ileri sürmüşlerdir ${ }^{32}$. Buna rağmen yine Asur coğrafyasında MÖ 9. asırda kenevirin tıbbi ilaç olarak kullanıldığına dair bilgiler literatürde yer almaktadır ${ }^{33}$. Bu tartışmalar gösteriyor ki eski çağda Sumerliler'den Yeni Asur çağına kadarki dönemde kenevirin Mezopotamya'daki varlığ 1 şüphelidir.

\section{4-Anadolu:}

Kenevirin bir tekstil malzemesi olarak da kullanıldığı düşünüldüğünde Mezopotamya ve Anadolu arasındaki en eski ticaret kayıtlarında ismi geçmesi gerekmektedir. Kültepe tabletlerinde kumaş kelimesi için genel tabirlerden biri "lubuštum" olarak geçmektedir ${ }^{34}$. Bu kelime gümünüze libas yani elbise olarak gelmiş olabilir. Asur ticaret koloni çağından (MÖ 1950-1750) günümüze kalan kil tabletlerde kırk civarında farklı kumaş türü ticaret emtiası olarak kaydedilmiştir. Buna karşın azallû veya qunabbu adında bir kumaş türüne rastlanmamıştır. Daha çok kenevire yakın olan keten ve yün türevi yüklerin transferinin sağlandığı kil tabletlerde yazmaktayken keneviri andıracak bir ürün ismine

\footnotetext{
${ }^{27}$ The Assyrian Dictionary Of The Oriental Institute Of The University Of Chicago, Editorial Board: J. Brinkman, M. Civil, I. J. Gelb, A. L. Oppenheim, E. Reiner, 1982, s. 306

${ }^{28}$ Age, s. 139

${ }^{29}$ A Concise Dictionary of Akkadian-CDA, Wiesbade, Editor: Black, Jeremy, Andrew George, Nicholas Postgate, Harrassowitz Verlag, https://archive.org/stream/AConsiceDictionaryAkkadian/CDA_w_corr_djvu.txt, 25.04. 2020

${ }^{30}$ Age

${ }^{31}$ R. C. Thompson, “Assyrian Prescriptions for Treating Bruises or Swellings”, The American Journal of Semitic Languages and Literatures, Vol. 47, No. 1, 1930, s. 16, 22

${ }^{32}$ A. Leo Oppenheim, "Essay on Overland Trade in the First Millennium B.C.", Journal of Cuneiform Studies, Vol. 21, Special Volume Honoring ProfessorAlbrecht Goetze 1967, s. 245

${ }^{33}$ M. Aldrich, "History Of Therapeutic Cannabis. In: Mathre ML, Eds. Cannabis In Medical Practice", Jefferson, NC: Mc Farland; 1997. s. 35, 55.

34 (1999), A Concise Dictionary of Akkadian-CDA, Wiesbade, Ed.Black, Jeremy, Andrew George, Nicholas Postgate, Harrassowitz Verlag, https://archive.org/stream/AConsiceDictionaryAkkadian/CDA_w_corr_djvu.txt, 25.04. 2020

\section{Corstory studies}


rastlanmamaktadır ${ }^{35}$. Bundaki temel nedenlerden biri yukarıda da iddia edildiği gibi Mezopotamya ve Anadolu'da bu bitkinin görünmemesi olabilir. Bir diğer neden kenevir varsa bile ondan üretilen kumaşın ismi farklı olup tabletlerde anlamı bilinmeyen kumaşlardan birine tekabül ediyor olabilir. Bir diğer neden olarak da bu bitki bu coğrafyalarda varsa bile ondan elde edilen ürünlerin ticari değerinin olmaması gösterilebilir.

Kenevir bitkisinin eski çağda Çin'de inşaatlarda ve denizcilikte kullanılan sağlam halatların yapımında kullanıldığı bilinmektedir. Özellikle Hititler'de ishamina, ishamanta, ishimanas gibi urgan anlamına gelen kelimelerin olması, Hititlerin bu urganları kenevirden imal ettiği fikrinin ileri sürülmesine neden olmuştur. Anadolu'da diğer bir ifade ile Hatti ülkesinde kenevirin Azullû ismiyle MÖ 16. asırda en azından urgan yapımı için üretilip kullanıldığı iddia edilmiştir ${ }^{36}$. Diğer taraftan Hitit uygarlığından sonra Anadolu'da yaşamış Friglerin merkezi Gordion'da bir kazı yapılmıştır. Bu kazı sonucunda MÖ 8. asırda yanmış bir yapıda korunabilmiş tekstil parçaları ve tekstil hammaddesi yetiştirmek üzere istiflenmiş tohumlar bulunmuştur. 2019'daki bir yayına göre bazı tohumların kenevir tohumu ile keten tohumundan ayırt edilemediği görülmüştür. Diğer bir ifade ile araştırmacılar şüpheye düşmüştür. Burada tekstil ürünlerinin bir yetiştirme deposu olduğu ve bazı tohumların kenevir tohumu olabilme ihtimalinden bahsetmekle birlikte kenevirin keten yerine kullanıldığının bir kanıtının da olmadığı bilgisi eklenmiştir ${ }^{37}$. Frigyalılar' 1 n tekstil konusunda ileri olduğu bilinmektedir. Gordion'da keten yetiştirildiği ve dokuması yapılmıştır. Fakat kenevirle eşitlenecek bir ürün kalıntısına net bir şekilde ulaşılamamışııı ${ }^{38}$. Kısacası Gordion gibi önemli bir tekstil merkezinde kenevirin olmaması bu dönemde hala kenevirin Anadolu'da tekstil malzemesi olarak yetiştirilip kullanılmadığının delilidir. Çünkü Hititler keneviri tekstil malzemesi olarak kullanmış olsalardı bu kültürün tekstil teknolojisinde önemli bir noktaya gelmiş Frigler'de de devam etmesi gerekirdi.

Volume 12

$\mathrm{Bu}$ muğlak bilgilere karşın Anadolu, Avrupa ve Akdeniz için kenevir bitkisini MÖ 5 . asırda orta Asya kökenli göçer bir halk olan İskitler tarafından getirildiği fikri hâkimdir ${ }^{39}$. İskitlerin merkezî Asya'dan Deşt-i Kıpçak ve Anadolu bozkırlarına ulaştığı bilinmektedir. Orta Asya'da Altay Dağlarında keşfedilmiş olan Pazırık Kurganında (MÖ 8.-7. yy) kenevir tohumları ve yakma aletleri bulunmuştur ${ }^{40}$. İşte bu yaygın kanaate göre kenevir Anadolu'ya Mezopotamya üzerinden değil Kafkasya üzerinden gelmiştir. Hatta İran'a dahi kenevir İskitler aracılığı ile gelmiştir. Herodotos'un bildirdiğine göre İskitler kenevir tohumlarıyla cenazelerden sonra tütsü yapıp yıkanma ayinleri tertipleyen göçer bir halktır ${ }^{41}$. Herodotos'un verdiği bilgiye göre kenevir Anadolu ve Avrupa'ya MÖ 5. asırda karayoluyla ulaşmıştır.

\footnotetext{
${ }^{35}$ Cahit Günbattı, Kültepe-Kaniş Anadolu'da İlk Yazı İlk Belgeler, Kayseri Büyükşehir Belediyesi Kültür Yayınları, s. 67, Ayrıca Bkz.:S. Saba Cebesoy, Kapadokya Tabletlerinde Geçen Dokuma Ürünleri, Anadolu Medeniyetler Müzesi 1994 Yıllı̆̆ı, Ankara 1995 s. 164-188

${ }^{36}$ Emre Dölen, Tekstil Tarihi, Marmara Üniversitesi Yayınları, 1992, s. 109

${ }^{37}$ S. Holzman, (2019), "Unfolding a Geometric Textile from 9th-Century Gordion", Hesperia: The Journal of the American School of Classical Studies at Athens, Vol. 88, No. 3, 2019, s. 531

${ }^{38}$ John M. Marston, Agricultural Sustainability And Environmental Change At Ancient Gordion, Gordion Special Studies VIII, University Pennsylvania Museum Of Archaeology And Anthropology, Philadelpia, 2017 s. 120

${ }^{39}$ A. W. Zuardi, agm, s. 154

${ }^{40}$ D. Stein, "The Role Of Stimulants In Early Near Eastern Society: Insights Through Artifacts And Texts", At the Dawn Of History Ancient Near Eastern Studies In Honour of J. N. Postgate, Winona Lake, Eisenbrauns, 2017 s. 512

${ }^{41}$ Herodotes, Tarih, Hasan Ali Yücel Klasikleri, Çev. Müntekim Ökmen, Türkiye İş Bankası Kültür Yayınları, s. 161
} 
Eski Çağda Kenevir Bitkisinin Kullanım ve Yayılımı Hakkında Yeni Bir Değerlendirme

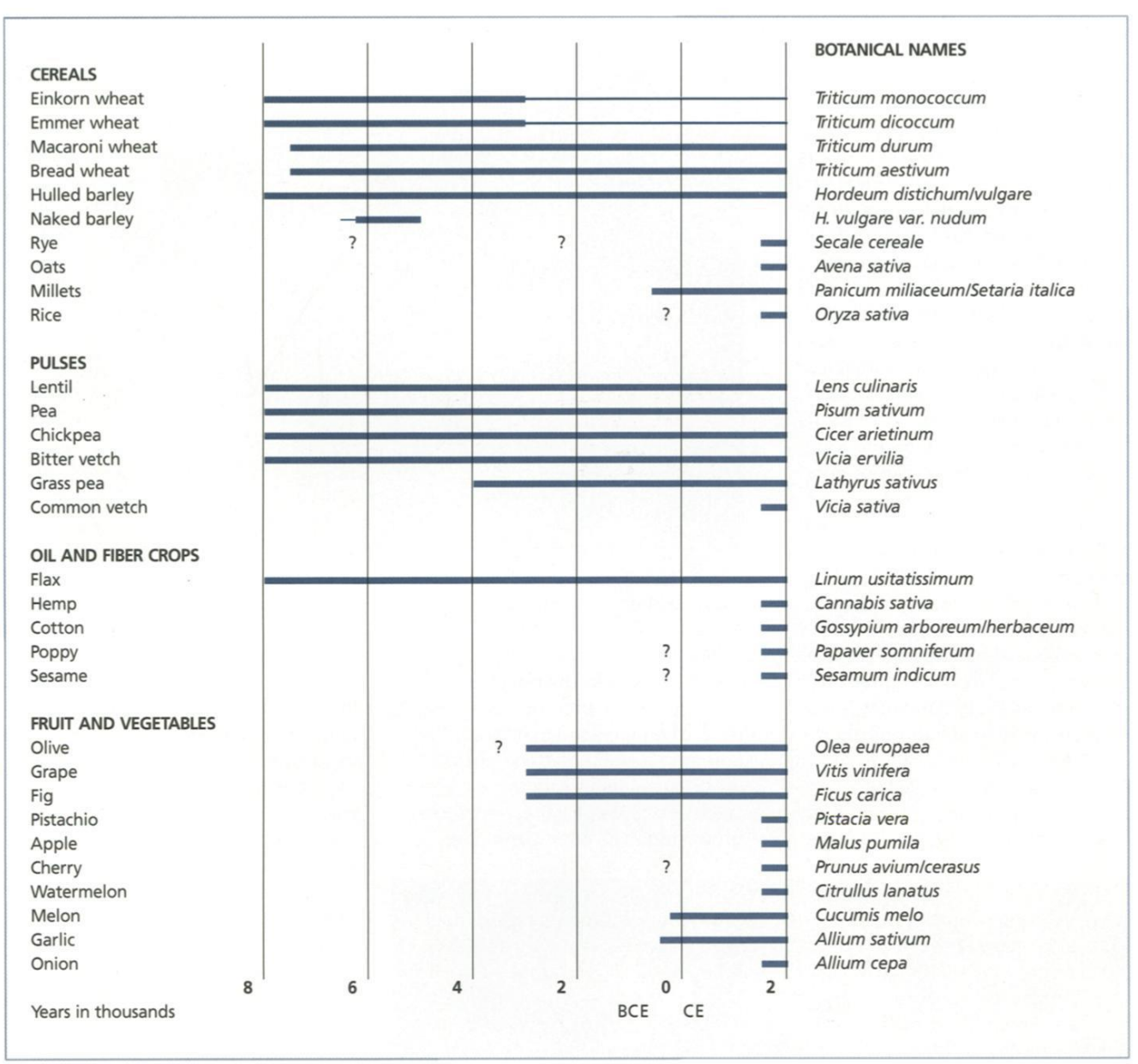

Tablo $1^{42}$

Yukarıdaki tabloda milattan sekiz yüz yıl önceden Geç Roma zamanına kadar Anadolu'da ekilen ürünlerin geçmiş çizelgesi verilmiştir. Tabloda Cannabis Sative olarak geçen kenevirin Anadolu'da ancak milattan sonraki yıllarda ekilmeye başladığı anlaşılmaktadır. Eğer ekilmiyorsa da Anadolu'ya ticaret vasıtasıyla gelmesi lazım gelmektedir. Çünkü yukarıda bahsedildiği gibi kenevirin kullanıldığına dair bazı iddialar mevcuttur. Fakat gerek Kültepe tabletlerinde gerekse de diğer ticaret arşivlerinde kenevirin adını doğrudan karşılayacak bir emtia yoktur. Kenevirin Mezopotamya'dan gelmesi muhtemelken ve azallû isimli bitkinin kenevir olma ihtimali hala şüpheliyken azallû, gurgurru ve qunnabu gibi isimlerin belgelerde yer almaması kenevirin Anadolu'ya geç tarihlerde girebildiği fikri rasyonel görünmektedir. Zira Anadolu'da bitkilerden elde edilen ilaç ve kumaşlarla ilgili güncel çalışmalarda kenevire rastlanmamaktadır ${ }^{43}$.

\footnotetext{
${ }^{42}$ M. Nesbitt, "Plants and People In Ancient Anatolia", The Biblical Archaeologist, Vol. 58, No. 2, Anatolian Archaeology: A Tribute to PeterNeve, 1995, s. 75

${ }^{43}$ Serkan Demirel- Uğur Çakılcılıŏlu, "Identification Of Medical Plants In Hittite Cuneiform Scripts", Belleten, C. LXXXI, S: 291, TTK, Ankara 2017, s. 305-328. Ayrıca Bkz: Yusuf Kılıç-Sekan Başol, "Hitit Büyü Metinlerinde Geçen Bazı Otsu Bitkiler, Ağaç Türleri Ve Ahşap Nesneler”, Akademik Tarih Ve Düşünce Dergisi, C. 2, S: 6, 2015, s. $28-58$
} 
Yukarıdaki bilgi ve sonuçlar göz önünde bulundurulduğunda kenevir Anadolu'ya ancak eski çağın son döneminde ulaşmıştır. Fakat yakın bir zamanda yapılan bir arkeolojik keşif bakış açımızı değiştirmemize sebep olmuştur. Bu keşifle kenevirin eski çağdan da önce neolitik dönemde Anadolu'da var olduğu ispatlanmıştır. 2013 Çatalhöyük kazı raporlarına göre F.3694 nolu platform kazılmıştır. Platformda bir mezarla karşılaşılmış ve içinden olgun bir erkeğe ve dört çocuğa ait olmak üzere 5 iskelet bulunmuştur. Bulunan çocuk iskeletlerin arasında kendir ${ }^{44}$ ile dokunmuş keten bir kumaş parçası gün yüzüne çıkarılmıştır. Bir bebek kundağ1 olduğu düşünülen bez oldukça iyi muhafaza edildiği arkeologlar tarafından gözlemlenmiştir. Bezin keten ve kenevirden imal edildiği laboratuvar sonuçları ile kesinleşmiştir. Çatalhöyük kazı başkanı Ian Hodder'e göre bu bez malzemelerinin değiş tokuş yöntemi ile Doğu Akdeniz'den Anadolu'ya ithal edildiği düşünülmektedir ${ }^{45}$.

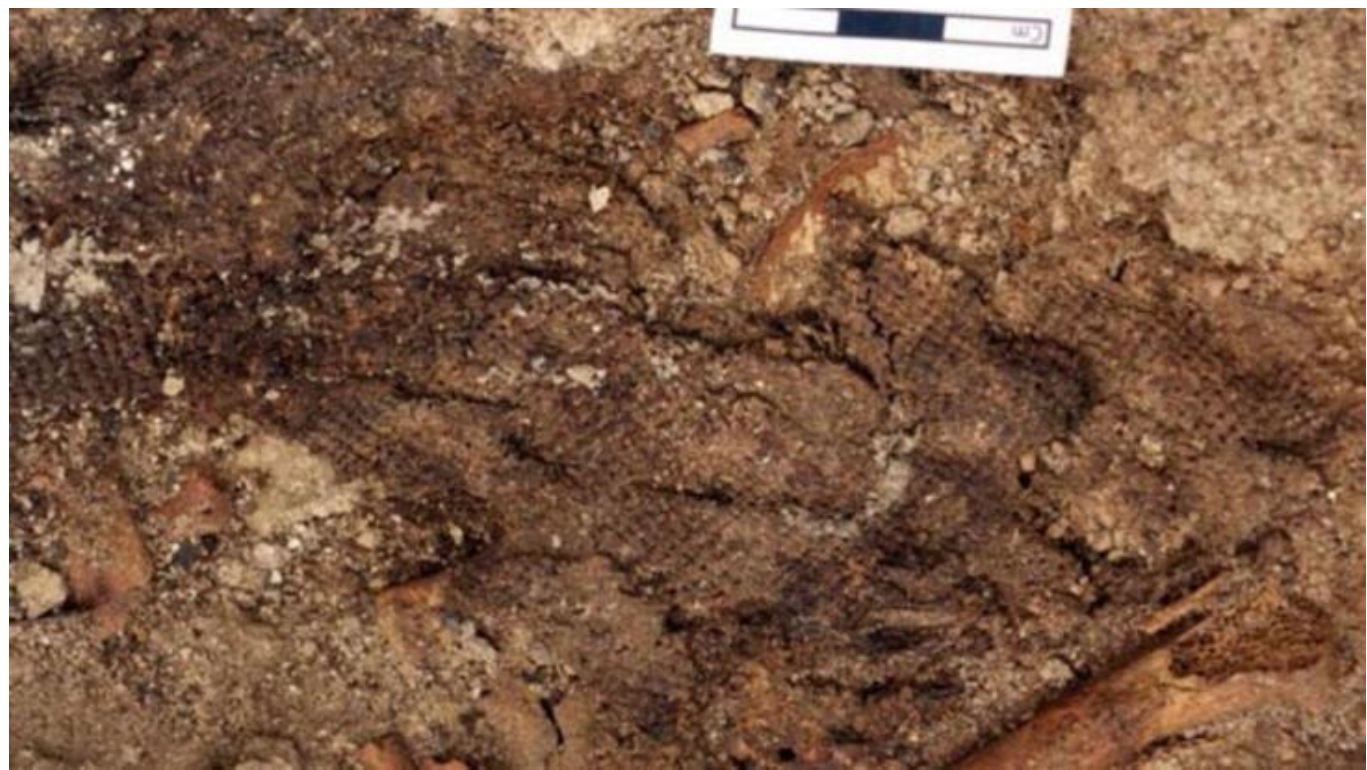

Resim: $1^{46}$ Çatalhöyük’te Bulunan Keten-Kenevir Mamulü Kumaş

Bu keşfe göre çok erken bir dönemde Anadolu'ya giren kenevir lifleri dokuma alanında kullanılmıştır. Fakat kenevirin Anadolu'da ancak eskiçağın son evresinde üretildiği ve diğer alanlarda kullanıldığı düşünülmektedir. Bu bitkinin Hitit ve de demir çağında Anadolu'da üretilip diğer alanlarda da kullanıldığına dair kuvvetli deliller henüz mevcut değildir. Ama neolitik dönemde değiş tokuş yöntemiyle kenevir, Anadolu'da tüketim malzemesi olmuştur.

Eskiçağın son dönemlerinde ise Ephesos'ta (Selçuk) kendir işçilerinin bulunduğu Alabanda (Aydın-Çine/Araphisar)'da ekilip yetiştirildiği, Mylasa (Muğla-Milas) ve Alabanda şehirlerinde ağ yapımında kenevirin kullanıldığı bilinmektedir ${ }^{47}$. Buradan da anlaşıldığına göre

\footnotetext{
${ }^{44}$ Kendir: 1. İsim, bitki bilimi Kenevir. 2. Sıfat Kenevirden yapılmış. Türk Dil Kurumu Sözlükleri, 23. 04. 2020, https://sozluk.gov.tr/

${ }^{45}$ Ian Hodder, "Çatalhöyük 2013 Kazı Raporu”, Dünya Kültür Miras Listesi’ne Alınan Bir Kazıda Çalışmak, 2014 s. 2,8

${ }^{46}$ https://www.milliyet.com.tr/gundem/catalhoyukte-buyuk-kesif-1830031, 23. 03.2020

47 A. Civelek, "Kendir-Kenevir", http://apelasyon.com/Yazi/846-kendir-kenevir, 23. 04. 2020
} 
kenevir deniz sanayi için halat ve ağ üretmek için eski çağın son kertesinde Anadolu'da ekilmeye başlamıştır.

\section{5-Avrupa:}

Kenevirin batı dünyasına İskitler vasıtası ile geldiği bilgisine yukarıda değinilmiştir. Strabon (MÖ 64 - MS 24) Balkanlar'da, Karpatya topraklarındaki Geate adlı Trakyalı bir kabilenin şamanları Kapnobatai dedikleri bir çiçeği sigara gibi içerek dans edip keyif aldıklarından bahsetmektedirr ${ }^{48}$. Bunun kenevirden elde edilen esrar olduğu tam olarak bilinmemekle beraber kullanım tarzının esrarı andırması ve İskitlerdeki şamanların kullanış tarzına benzemesi bu bitkinin kenevir olma ihtimalini oldukça kuvvetlendirmektedir. MÖ 1 . asırda yaşamış Kilikyalı hekim Dioscorides bitkiler üzerine ciddi çalışmaları olan bir eski çağ bilim insanıdır. O kenevir bitkisinden bahsederken kannabion ismini kullanmıştır. $\mathrm{Bu}$ isim modern bilimde kullanılan cannabis kelimesinin ilk hali olmalıdır ${ }^{49}$. Dolayısıyla batı dünyası için kenevirin adını o koymuştur denebilir. De Materia Medica adlı eserle ilgili bir makalede kenevirin ilaç ve tekstil için önemli bir hammadde olduğunu ayrıca suyunun içilebildiği yazarken psikoaktivite için kullanımı hakkında bilgi verilmemektedir ${ }^{50}$.

Kenevir hakkında tespitlerde bulunan bir diğer antik çağ hekimi Bergamalı Galen' (MS 129-199) dir. Luigi Arata'nın makalesine göre Galen, bu bitkiye kephalalgès adını vermektedir. Roma'da saray hekimliği de yapan Galen kenevirin psikoaktif etkisinin yanında iyi bir ağrı kesici olduğundan bahsetmiştir. Meyvesinin fazla tüketilmesinin bazı zararlar doğurabileceğini de eklemiştir ${ }^{51}$.

Kenevir eski çağın son kertelerinde tıp ve psikoaktivite ürünü olma dışında tekstil ürünü olarak da kullanılmıştır. R. C. Clarke ve Mark D. Merlin'in kitabında Athenaeus'un kenevirle ilgili ifadesi yer almaktadır. Buna göre Yunan tiranlarından II. Hieron (MÖ 270-215), İspanyadan kenevir ithal etmiştir. İthal edilen bu kenevir gemi teknolojilerinde kullanmak üzere alınmışııิ ${ }^{52}$. Bu tarihlerden daha öncesinde Akdeniz gemi teknolojisinde kenevir ile ilgili pek ciddi bilgi yoktur. Keza eski çağ Akdeniz gemi yelken ve halatları genelde keten ve papirüslerden imal edilmektedir. Herodotus kendi döneminde Misır gemilerinin yelkenlerinin papirüsten yapıldığına işaret etmektedir. Fakat Herodotus ile çağdaş olan 5. Hanedan dönemine ait ikonografilerden bu yelkenlerin keten olduğu anlaşılmaktadır ${ }^{53}$. Bu bilgiler 1şı̆̆ında MÖ 5. asırda Akdeniz denizciliğinde kenevir teknolojisi henüz erken görünmektedir. $\mathrm{Bu}$ ifade kenevirin Akdeniz'de bu dönemden önce bilinmediği anlamına gelmemektedir. Tevrat'ta kenevir ile ilgili ayetler yer almaktadır ${ }^{54}$.

Kenevirin Avrupalı denizcilerle tanışması oldukça geç olmuştur. MS ilk asırda kenevir tarımı yapılmaya başlanmıştır ${ }^{55}$. Geç Roma dönemindeki gemiciler kenevirden mamul halatlar yapmışlardır. İskandinavya'da ise MS 20-220 yıllarına ait kenevir fosilleri bulunsa da gemiciler tarafindan ancak MS 10. asırda keneviri ileri gemi teknolojisinde kullandıkları

\footnotetext{
${ }^{48}$ Strabon, Geographia VII, 3, s. 17

49 J. L. Butrica, "The Medical Use of Cannabis Among the Greeks and Romans", Journal of Cannabis Therapeutics, Vol. 2, 2 2002, s. 525

${ }^{50}$ F.J. Carod-Artal, "Psychoactive Plants In Ancient Greece", Neurosciences and History 2013; 1 (1), s. 34

${ }^{51}$ Luigi Arata, "Nepenthes and Cannabis in Ancient Greece", Janus Head, 7,(1), New York, s. 41

${ }^{52}$ R. C. Clarke-Mark D. Merlin, Age, s. 160

${ }^{53}$ Steve Vinson, "The Earliest Representations of Brailed Sails”, Journal Of The American Research Center In Egypt, Vol. 30, 1993, s. 144

${ }^{54}$ Tevrat, Hakimler16/9: Adamları bitişik odada pusuya yatmıştı. Delila, "Şimşon, Filistliler geldi!" dedi. Şimşon sırımları ateş değdiğinde dağılıveren kendir lifleri gibi koparıp attı. Gücünün sırrını vermemişti.

${ }^{55}$ Mikael Larsson, Per Lageras, "New Evidence On The Introduction, Cultivation And Processing Of Hemp (Cannabis sativa L.) In Southern Sweden”, Environmental Archaeology, Vol. 1, No: 1, 2014, s. 7
} 
düşünülmektedir. Bu da demek oluyor ki kenevir Avrupa gemi teknolojisiyle geç tanışmıştır. $\mathrm{Bu}$ noktada Vikingler akıllara gelmektedir. Onların deniz teknolojisinde keneviri kesinkes kullanmış oldukları bilinmektedir. Yelken ve halatlarını kenevirden elde etmişlerdir ${ }^{56}$.

Kenevirden elde edilen malzemeler uzun ömürlüdür ${ }^{57}$. Kenevirden yapılan halatlar, yelkenler ve yelken armaları keten, papirüs ve diğer muadil lifli bitkilerden elde edilen kumaşlardan çok daha dayanıklıdır. Bu da gemilerin denizde kalma sürelerini arttıran bir husustur. Akdeniz bir iç deniz olması hasebiyle okyanuslara göre daha az rüzgârlıdır. Buradaki yelken teknolojisi de buna göre gelişmiştir. Ancak kenevir halatların ve yelkenlerin kullanılması sayesinde Akdeniz gemicileri daha uzun seferler yapabilir hale gelmiştir. Örneğin MS 1492'de dünyanın kaderini değiştiren Yeni Dünya'nın (West-India) keşfi olayında C. Colombus'un gemileri kenevir halatlar ve yelken armaları ve kabloları ile donatılmıştı ${ }^{58}$.

\section{Sonuç:}

Sonuç olarak eski çağda kenevirin insanlar tarafından birçok alanda kullanıldığı görülmüştür. Tekstil, tıp, kâğıt ve deniz teknolojilerinin aranan lifli malzemesi olarak değerlendirilen kenevir, içindeki uyarıcı etmenler nedeniyle keyif verici uyuşturucu maddesi olarak da eski çağ insanı tarafından kullanılmıştır. Bu son özelliği sebebiyle doğduğu merkezi Asya ve Hindistan'da dinsel törenlerde de kullanıldığı görülmüştür.

Kenevirin ilaç olarak da kullanılması nedeniyle bazı araştırmacıların Mezopotamya'da isimleri geçen diğer ilaç olarak kullanılan bitkilerle karıştırmasına sebebiyet vermiştir. Fakat bu bitkilerin kenevir olduğu hususunda ne maddi-arkeolojik ne de sağlama yapılacak yazınsal metnin olmadığı görülmüştür. Aynı husus Anadolu için de geçerlidir. Bazı bilim insanları gerek demir çağında Frigyalılarca gerekse öncesinde Hititlerce kenevirin tekstil malzemesi olarak kullanıldığını iddia etmişlerdir. Bu durum Mezopotamya'daki gibi şüphelidir. Fakat Anadolu için bir istisna ile karşılaşılmaktadır. Çatalhöyük'te neolitik döneme ait kenevirle dokunmuş keten bezinin bulunması, çok erken dönemde kenevirin Anadolu'da tekstil malzemesi olarak kullanıldığını göstermektedir. Buna rağmen bu dönemde kenevir üretimi ile ilgili maddi bir delil yoktur. Bu yüzden kenevirin neolitik dönemde Anadolu'ya doğudan geldiği anlaşılmaktadır.

Başka bir sonuç olarak eski çă̆ gibi uzun bir zaman diliminde kenevir önce eski çağ evvelinde neolitik dönemde daha sonrada eski çağın son kertesinde Anadolu'da görülmüştür. Diğer bir ifade ile kenevir Anadolu'da bir üretim maddesi olarak ne neolitik dönemde ne Hitit çağında ne de Frigya döneminde yetiştirilmemiştir. Kenevir eski çağın başında ve ortasında değil antik Yunan çağında Anadolu'da bir üretim maddesi haline gelmiştir.

Çalışmada ulaşılan bir diğer sonuç ise şudur. Çin'de ve Hindistan'da oldukça erken dönemlerde endüstriyel bir malzeme olarak kullanılan kenevirle Avrasya'nın batısındaki uygarlıklar aynı teknolojik gelişme düzeyinde tanışmamışlardır. Kenevirin batıda uzun bir zaman geçtikten sonra doğu Asya'daki gibi deniz teknolojisinde kullanıldığı görülmüştür. Bunun temel nedeni de batılı halkların keneviri Hindistanlı, Malay veya Çinli denizciler aracılığı ile değil Asya steplerindeki atlı göçerlerin sayesinde tanımasıdır. Eğer batılı denizciler aynı tecrübe birikimiyle kenevir ile buluşmuş olsalardı; kenevirden halatlar ve kanvas (cannabis) yelkenler gibi dayanıklı malzemeleri daha erken kullanmış olabileceklerdi. Bu sebeple Yeni Dünyanın (Batı Hindistan-Amerika) keşfi daha erken tarihlerde gerçekleşme ihtimali doğabilirdi. Bu çalışmanın ulaştığı son sonuca göre kenevirin batıya geç gelmesi,

${ }^{56}$ R. C. Clarke-Mark D. Merlin, Age, s. 200

${ }^{57}$ Mikael Larsson-Per Lageras, agm, s.7

${ }^{58}$ T. Karche-M. R. Singh, agm, s. 717 
gelmesinden sonra da teknolojik ilerleme için zamana ihtiyacı olması, coğrafi keşiflerin zamanını da ertelemiş görünmektedir.

\section{Kaynakça}

ABEL, E. L., Marihuana The First Twelve Thousand Yeras, Springer Science Business Media, New York 1980.

ALDRICH, M. "History Of Therapeutic Cannabis. In: Mathre ML, Eds. Cannabis In Medical Practice", Jefferson, NC: Mc Farland; 1997. s. 35-55.

ARATA, Luigi, "Nepenthes And Cannabis In Ancient Greece", Janus Head, Vol. 7, No: 1, New York, s.34-49.

BENNET, C., Cannabis In The Ancient World, https://weekendsatbellevue.com/pdfs/potbook/bennett.pdf, 20.04. 2020.

BLACK, Jeremy, Andrew George, Nicholas Postgate, Harrassowitz Verlag, A Concise Dictionary Of Akkadian-CDA, Wiesbade, https://archive.org/stream/AConsiceDictionaryAkkadian/CDA_w_corr_djvu.txt, 25.04. 2020.

BRINKMAN, M.-Civil, I. J. Gelb, A. L. Oppenheim, The Assyrian Dictionary Of The Oriental Institute Of The University Of Chicago, Editorial Board: J, E. Reiner, 1982

BUTRICA, J. L., "The Medical Use Of Cannabis Among the Greeks and Romans", Journal Of Cannabis Therapeutics, Vol. 2, (2) 2002, s. 51-71

CAROD, F.J. -Artal, "Psychoactive Plants In Ancient Greece", Neurosciences And History 2013; 1 (1), s. 28-38

CEBESOY S. Saba, "Kapadokya Tabletlerinde Geçen Dokuma Ürünleri", Anadolu Medeniyetler Müzesi 1994 Yıllı̆̆

CIVELEK, A., "Kendir-Kenevir", http://apelasyon.com/Yazi/846-kendir-kenevir, 23. 04. 2020

CLARKE, R. C.-Mark D. Merlin, Cannabis Evolition And Ethnobotany, University Of California Press, Berkeley, Los Angeles, London, 2013.

DEMIREL, Serkan- Uğur Çakılcılığlu, "Identıfıcatıon Of Medical Plants In Hittite Cuneiform Scripts", Belleten, C. LXXXI, S: 291, TTK, Ankara2017, s. 305-328

DÖLEN, Emre, Tekstil Tarihi, Marmara Üniversitesi Yayınları, İstanbul 1992.

DUWALL, Chris, Cannabis, Reaktion Books, London, 2014.

GÜNBATTI, Cahit, Kültepe-Kaniş Anadolu'da İlk Yazı İlk Belgeler, Kayseri Büyükşehir Belediyesi Kültür Yayınları, Kayseri 2017.

HERODOTES, Tarih, Hasan Ali Yücel Klasikleri, Çev. Müntekim Ökmen, Türkiye İş Bankası Kültür Yayınları, 2008.

HODDER, Ian. "Çatalhöyük 2013 Kazı Raporu”, Dünya Kültür Miras Listesi’ne Alınan Bir Kazıda Çalışmak, catalhoyuk.com, 23. 04. 2020.

HOLZMAN, S., (2019), "Unfolding A Geometric Textile From 9th-Century Gordion", Hesperia: The Journal Of The American School of Classical Studies At Athens, Vol. 88 , No. 3, s. 527-556.

\section{History Studies}


KARCHE, T.-M. R. Singh, "The Application Of Hemp (Cannabis Sativa L.) For A Green Economy: A Review", Turkish Journal of Botany, 43, 2019, s. 710-723.

KILIÇ, Yusuf-Sekan Başol, "Hitit Büyü Metinlerinde Geçen Bazı Otsu Bitkiler, Ağaç Türleri Ve Ahşap Nesneler", Akademik Tarih Ve Düşünce Dergisi, C. 2, S: 6, 2015, s. 28-58.

KUDDUS, M., Gınavı, I. A, El-Hazımî, A., "Cannabis Sativa: An Ancient Wild Edible Plant Of India”, Emir. J. Food Agric. 2013. 25 (10): s. 736-745.

LARSSON, Mikael, Per Lageras, "New Evidence On The Introduction, Cultivation And Processing Of Hemp (Cannabis sativa L.) In Southern Sweden", Environmental Archaeology, Vol. 0, No: 0, 2014, s. 1-9.

MARSTON, John M., Agricultural Sustainability And Environmental Change At Ancient Gordion, Gordion Special Studies VIII, University Pennsylvania Museum Of Archaeology And Anthropology, Philadelpia, 2017.

MERLIN, M. D., "Archaeological Evidence For The Tradition Of Psychoactive Plant Use In The Old World”, Economic Botany, Vol. 57, No. 3, New York, 2003, s. 295-323. BITT, M., "Plants And People In Ancient Anatolia", The Biblical Archaeologist, Vol. 58,

NESBITT, M., "Plants And People In Ancient Anatolia”, The Biblical Archaeol
No. 2, Anatolian Archaeology: A Tribute To PeterNeve, 1995, s. 68-81.

NEWTON, D. E., Marijiuana, ABC -CLIO, Santa Barbara, California, Denver, Colorado, 2017.

OPPENHEIM, A. Leo, "Essay On Overland Trade In The First Millennium B.C.”, Journal Of Cuneiform Studies, Vol. 21, Special Volume Honoring ProfessorAlbrecht Goetze 1967, s. $236-254$.

RÄTSCH, C., Marijuana Medicine: A World Tour Of The Healing And Visionary Powers Of Cannabis, Healing Arts Press, Rochester-Newyork Vermonts, 2001.

RUSSO, E. B., "The Pharmacological History Of Cannabis", Chapter 2, Constituents, History, International Control, Cultivation, And Phenotypes Of Cannabis, Oup-First Uncorrected Proof, May 12, 2014, s. 23-43.

SAYIN, H. Ü., "The Consumption Of Psychoactive Plants During Religious Rituals: The Roots Of Common Symbols And Figures In Religions And Myths", NeuroQuantology, No. 2, 2014, s. 276-296.

SHAFFER, Lynda, "Southernization", Teaching World History: A Resource Book, Editor: Heidi Roupp, M. E. Sharpe, London 1997. s. 110-118

STEIN, D., (2017), "The Role Of Stimulants In Early Near Eastern Society: Insights Through Artifacts And Texts", At the Dawn Of History Ancient Near Eastern Studies In Honour of J. N. Postgate, Winona Lake, Eisenbrauns, 2017, s. 512-567.

STRABON, Geographia VII, 3

TEVRAT, Hakimler16/9, https://www.bursakilisesi.com/kutsalkitap/ 24.05.2020

THOMPSON, R. C., "Assyrian Prescriptions For Treating Bruises Or Swellings", The American Journal Of Semitic Languages And Literatures, Vol. 47, No. 1, 1930, s. 1-25

TOUW, Mia, "The Religious And Medicinal Uses Of Cannabis In China, India And Tibet", Journal of Psychoactive Drugs, Vol. 13(1), 1981, s. 1-12. 
TSIEN, Tsuen-Hsuin, "Raw Materials For Old Papermaking in China", Journal Of The American Oriental Society, Vol. 93, No. 4, 1973, s. 510-519.

VINSON, Steve, "The Earliest Representations Of Brailed Sails", Journal Of The American Research Center in Egypt, Vol. 30, 1993, s. 133-150.

WARF, B., "High Points: An Historical Geography Of Cannabis", Geographical Review, New York, 104, (4), s. 414-438.

ZUARDI, A. W., "History Of Cannabis As A Medicine: A Review", Rev Bras Psiquiatr. 2006; 28(2), s.153-157.

Türk Dil Kurumu Sözlükleri, https://sozluk.gov.tr/, 23. 04. 2020

https://www.milliyet.com.tr/gundem/catalhoyukte-buyuk-kesif-1830031, 23. 04. 2020 